\title{
'|||||||||||||||||||||||||||||||||||||||||||||||||||||||||||||||||.
}

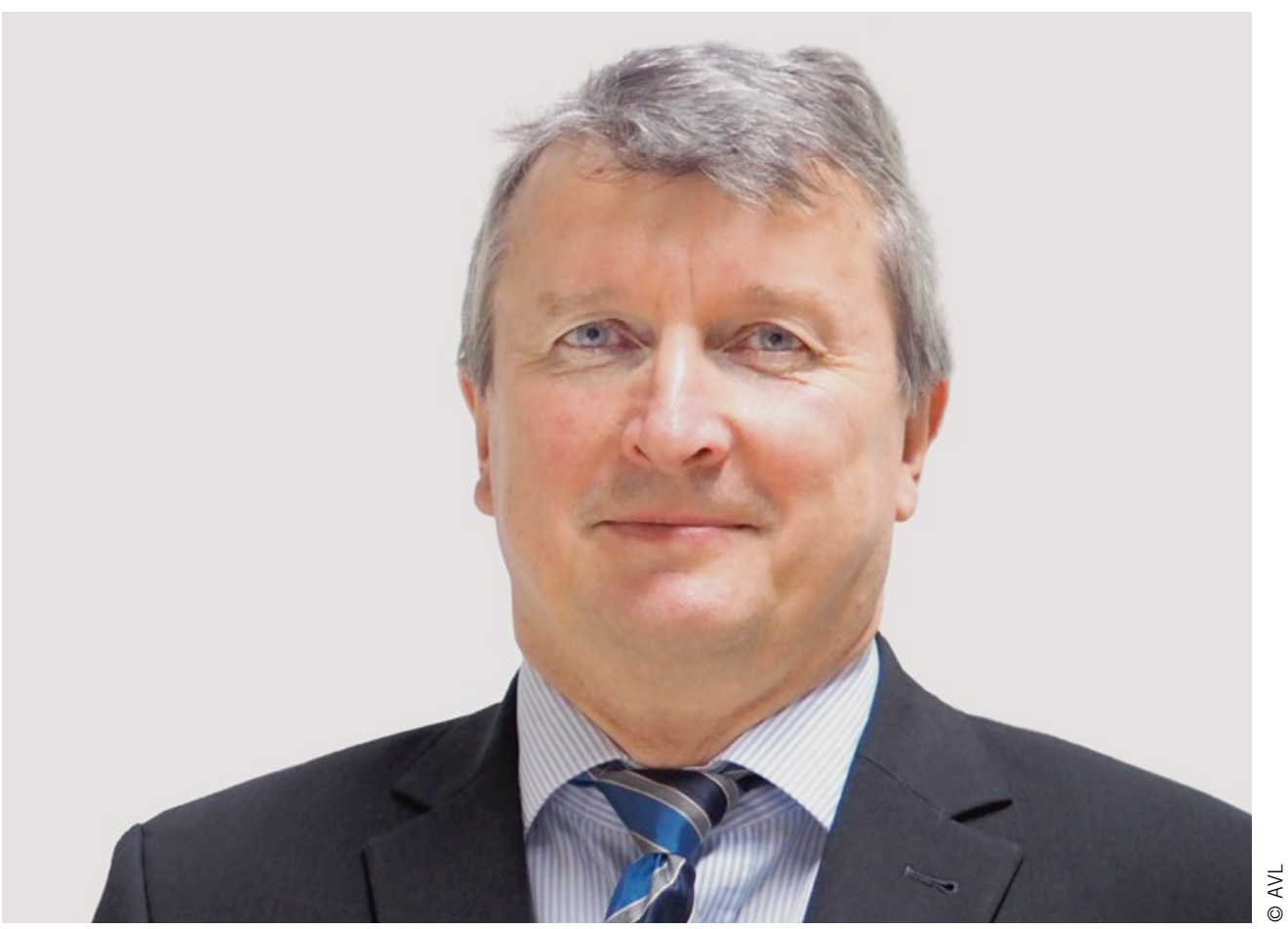

Dr.-Ing. Hagen Adam

Managing Director and Business Field Manager Off-Road,

AVL Commercial Driveline \&

Tractor Engineering $\mathrm{GmbH}$

\section{Höher, schneller, intelligenter}

Die Landwirtschaft in Mittel- und Westeuropa ist eine Industrie mit den höchsten Produktivitätszuwächsen überhaupt. So hat ein Landwirt vor etwa 70 Jahren zwei bis drei Menschen ernährt, heute sind es circa 120 Menschen! Wir sehen heute in vielen Bereichen hochentwickelte Maschinen, deren Leistungsvermögen enorm groß ist. Wir sehen aber auch, dass die Effizienz und Produktivität nicht adäquat wächst ohne entsprechend intelligente Steuerungen in den Maschinen. Die Hersteller haben reagiert und stellen hochintelligente Systeme zur Verfügung - nicht immer einfach zu bedienen, jedoch in der Lage, die durchschnittliche Nutzung der installierten Leistung zu optimieren.

Der nächste Schritt ist die digitale Vernetzung der Maschinen, allein schon deshalb eine riesige Herausforderung, weil auf einem Betrieb typischerweise Maschinen unterschiedlicher Hersteller stehen. Hier ist die Landtechnik über verschiedene Plattformen und dank der Verbandsarbeit auf einem guten Weg und deutlich weiter als andere Industrien.

Bei der heute immer anspruchsvolleren Absicherung der Ernährung der wachsenden Bevölkerung sind vor allem Themen wie Produktivität, Präzision, Nachhaltigkeit und Dokumentation sowie Umweltschutz auch im Sinne der Erhaltung der Produktionsgrundlage die wesentlichen Treiber. Der Schlüssel dazu heißt Flexibilisierung der Technik mit dem Ziel der kontextbezogenen Nutzung von
Technik und Betriebsmitteln. Das bezieht sich auch auf die Antriebstechnik.

$\mathrm{CO}_{2}$-Reduzierung heißt Reduzierung des Verbrauchs von Energie, bezogen auf die Arbeitsprozesse. Genauso wichtig sind jedoch die gezielte und nach Möglichkeit auf Einzelpflanzen bezogene Ausbringung von Pflanzenschutz und Pflanzennahrung - alles bei noch besserer Produktivität! Hochentwickelte Sensorik, flexible und präzise Aktorik und Antriebstechnik sowie effiziente Kommunikation sind hier der Schlüssel zum Erfolg. So bekommt zum Beispiel elektrische Antriebstechnik, circa 10 Jahre nach Einführung erster Serienfahrzeuge in der Landtechnik, heute einen neuen Stellenwert. Leistungsbereitstellung von 10 bis $20 \mathrm{~kW}$ vom Traktor für Implements in einem stabilen Versorgungsnetz zu verträglichen Kosten und vor allem mit hoher Zuverlässigkeit sind dabei eine Plattform für viele Anwendungen. Die Entwicklungen der 48/80-V-Technologie für Nutzfahrzeuge, Pkw und Flurförderfahrzeuge bieten hier zukünftig Technologien und Komponenten an.

Bei allen Zielen für die neuen Technologien gibt es aus meiner Sicht zwei wesentliche. Für die Nutzer müssen sie helfen, die Betriebskosten bei hoher Zuverlässigkeit der Maschinen zu senken. Für die Öffentlichkeit müssen die neuen Technologien helfen, die Wahrnehmung der Landwirtschaft über nachvollziehbare und dokumentierte Prozesse weiter positiv zu gestalten. 